\title{
Postmenopausal weight change and incidence of fracture: post hoc findings from Women's Health Initiative Observational Study and Clinical Trials
}

\author{
Carolyn J Crandall, ${ }^{1}$ Vedat O Yildiz, ${ }^{2}$ Jean Wactawski-Wende, ${ }^{3}$ Karen C Johnson, ${ }^{4}$ Zhao Chen, ${ }^{5}$ \\ Scott B Going, ${ }^{6}$ Nicole C Wright,7 Jane A Cauley ${ }^{8}$
}

${ }^{1}$ David Geffen School of

Medicine at University of

California, Los Angeles, Division

of General Internal Medicine

and Health Services Research,

UCLA Medicine/GIM, 911

Broxton Avenue, 1st floor, Los

Angeles, CA, 90024, USA

${ }^{2}$ Center for Biostatistics, Ohio

State University, 2012 Kenny

Road, Columbus, Ohio, USA

${ }^{3}$ Department of Social and

Preventive Medicine, University

at Buffalo, State University of

New York, 65 Farber Hall, 3435

Main Street, Buffalo, NY

14214-3000 State University of

NY at Buffalo, Buffalo, NY, USA

${ }^{4}$ Department of Preventive

Medicine, University of

Tennessee Health Science

Center, 66 N. Pauline, Suite 633,

Memphis, TN 38163, USA

${ }^{5}$ Division of Epidemiology and

Biostatistics, University of

Arizona, Tucson, Arizona, USA

${ }^{6}$ Department of Nutritional

Sciences, University of Arizona,

Tucson, Arizona, USA

7Department of Epidemiology,

University of Alabama at

Birmingham, RPHB 523C,

Birmingham, AL, 35294, USA

${ }^{8}$ Department of Epidemiology,

Graduate School of Public

Health, University of Pittsburgh,

Pittsburgh, PA, USA

Correspondence to: C J Crandall

ccrandall@mednet.ucla.edu

Additional material is published

online only. To view please visit

the journal online (http://

dx.doi.org/10.1136/BMJ.h25)

Cite this as: $B M J$ 2015;350:h25

Accepted: 05 December 2014

\section{ABSTRACT}

OBJECTIVES

To determine associations between postmenopausal change in body weight and incidence of fracture and associations between voluntary and involuntary weight loss and risk of fracture.

DESIGN

Post hoc analysis of data from the Women's Health Initiative Observational Study and Clinical Trials.

SETTING

40 clinical centers in the United States.

\section{PARTICIPANTS}

120566 postmenopausal women, aged $50-79$ at baseline (1993-98), followed through 2013 (mean fracture follow-up duration 11 years from baseline).

\section{EXPOSURES}

Annualized percentage change in measured body weight from baseline to year 3 , classified as stable ( $<5 \%$ change), weight loss ( $\geq 5 \%$ ), or weight gain $(\geq 5 \%)$. Self assessment of whether weight loss was intentional or unintentional. Cox proportional hazards regression models were adjusted for age, race/ ethnicity, baseline body mass index (BMI), smoking, alcohol intake, level of physical activity, energy expenditure, calcium and vitamin D intake, physical function score, oophorectomy, hysterectomy, previous fracture, comorbidity score, and drug use.

\section{MAIN OUTCOMES}

Incident self reported fractures of the upper limbs, lower limbs, and central body; hip fractures confirmed by medical records.

RESULTS

Mean participant age was 63.3. Mean annualized percent weight change was $0.30 \%$ (95\% confidence

\section{WHAT IS ALREADY KNOWN ON THIS TOPIC}

Low body weight is associated with increased risk of fracture

However, associations of weight loss and weight gain with subsequent fracture incidence, classified by anatomical region, in postmenopausal women are unclear. How fracture patterns may differ after intentional and unintentional weight loss in postmenopausal women is also unknown

\section{WHAT THIS STUDY ADDS}

Weight gain, weight loss, and even intentional weight loss are associated with increased fracture incidence, but associations differ by anatomical fracture location. Our findings challenge the traditional clinical model of weight gain being protective against fractures

Clinicians should be aware of fracture patterns both after weight gain and weight loss

interval 0.28 to 0.32$)$. Overall, $79279(65.6 \%)$ had stable weight; 18266 (15.2\%) lost weight; and 23021 (19.0\%) gained weight. Compared with stable weight, weight loss was associated with a $65 \%$ higher incidence rates of fracture in hip (adjusted hazard ratio 1.65, 95\% confidence interval 1.49 to 1.82$)$, upper limb $(1.09,1.03$ to 1.16), and central body $(1.30,1.20$ to 1.39$)$; weight gain was associated with higher incidence rates of fracture in upper limb $(1.10,1.05$ to 1.18$)$ and lower limb $(1.18,1.12$ to 1.25). Compared with stable weight, unintentional weight loss was associated with a $33 \%$ higher incidence rates of hip fracture $(1.33,1.19$ to 1.47$)$ and increased incidence rates of vertebral fracture $(1.16,1.06$ to 1.26$)$; intentional weight loss was associated with increased incidence rates of lower limb fracture $(1.11,1.05$ to 1.17$)$ and decreased incidence of hip fracture $(0.85,0.76$ to 0.95$)$.

\section{CONCLUSIONS}

Weight gain, weight loss, and intentional weight loss are associated with increased incidence of fracture, but associations differ by fracture location. Clinicians should be aware of fracture patterns after weight gain and weight loss.

\section{Introduction}

The influence of body weight on the risk of fracture is complex. Low body weight is considered a risk factor for osteoporotic fracture. ${ }^{1}$ There is, however, increasing recognition that a high proportion of postmenopausal women with low trauma fractures are obese. ${ }^{2}$ Moreover, beyond low body weight per se, change in body weight can have an important influence on risk of fracture. For example, longitudinal studies of postmenopausal white women in the United States have found that weight loss increases the risk of subsequent hip and other frailty fractures. ${ }^{3-6}$ Similar studies of postmenopausal non-white women are lacking, yet differences in body weight distributions ${ }^{7}$ and absolute risk of fracture ${ }^{8}$ across racial groups are striking.

There is also a paucity of information on whether the influence of weight change on subsequent risk of fracture varies by anatomical site. In longitudinal studies of white women aged $\geq 65$, weight loss measured in various ways (over four years or since maximum weight or since age 50) was associated with an increased risk of hip fracture, ${ }^{4-6}$ whereas weight gain since age 25 was associated with a higher risk of ankle fracture. ${ }^{9}$ No longitudinal studies, however, have focused specifically on how weight change can differentially influence upper limb, lower limb, hip, and central body fractures among postmenopausal white or non-white women in the US. Also, few studies have considered the reason for underlying weight loss in the analysis of associations 
between weight loss and fractures. This distinction might be important because serious illness could be an underlying cause of both involuntary weight loss and osteoporosis. In one study, associations between weight loss and increased risk of frailty fracture were significant only among women reporting involuntary, but not voluntary weight loss, ${ }^{3}$ whereas in another study, voluntary and involuntary weight loss among overweight women were each associated with similar (2.5-fold) increases in risk of hip fracture. ${ }^{4}$ Neither of those two studies adjusted for baseline weight or body mass index (BMI).

We investigated associations between change in body weight (baseline to third annual visit) and subsequent incidence of fracture classified by anatomical region (for example, upper limb, lower limb, central body) among postmenopausal women and to what extent self reported voluntary and involuntary weight loss are associated with increased incidence of fracture. We hypothesized that associations between weight loss and increased fracture incidence would be more pronounced for hip fractures than for limb fractures because of the potential loss in soft tissue padding around the hip that could counteract traumatic forces. We also hypothesized that even voluntary weight loss would be associated with an increased incidence of hip fracture. We further postulated that weight gain would increase the incidence of limb fractures, as the upper and lower extremities have little overlying soft tissue to absorb the increased impact resulting from weight gain and because of poor neuromuscular conditioning.

\section{Methods \\ Women's Health Initiative Study}

We used data from the Women's Health Initiative Observational Study and the Women's Health Initiative Clinical Trials. At 40 clinical centers nationwide between 1993 and 1998, the Women's Health Initiative study enrolled postmenopausal women aged 50-79 at baseline who were free from serious cardiac, pulmonary, renal, and hepatic conditions and had at least three years' life expectancy. ${ }^{10-12}$ The three placebo controlled Women's Health Initiative clinical trials tested several interventions among postmenopausal women: a low fat eating pattern, menopausal hormone therapy, and calcium and vitamin D supplementation. ${ }^{12}$ The Women's Health Initiative Observational Study examined the predictors and natural course of important causes of morbidity and mortality in postmenopausal women. ${ }^{11}$ Recruitment details are available at https://cleo.whi. org/about/SitePages/About\%20WHI.aspx. The com-

$\overbrace{\text { Baseline } \quad \text { Year } \mathbf{3} \text { visit }}^{\begin{array}{c}\text { Weight change } \\ \text { assessment period }\end{array}}$

Fig 1. Weight change period in relation to fracture follow-up period. Mean follow-up duration was 11 years from baseline bined studies enrolled 161808 participants (93676 in the observational study and 68132 in the clinical trial). Our analytic sample consisted of 120566 participants from the two studies for whom information was available regarding weight change (from baseline to year three) and at least one year of follow-up (after the year three visit) regarding incident fractures (fig 1). Follow-up data were available for 31 March 1995 through 17 September 2013.

Participants were asked to complete baseline self assessment questionnaires. Weight and height were measured at baseline and at the third annual follow-up visit with standardized protocols. BMI was calculated as body weight in kilograms (kg) divided by the square of height in meters. Waist:hip ratio was calculated as the ratio of waist circumference $(\mathrm{cm})$ to hip circumference $(\mathrm{cm})$.

\section{Outcomes}

Our study outcome was incidence of fracture. Each year, participants were asked to report fracture events since the previous annual visit: "Has a doctor told you for the first time that you have a new broken, crushed, or fractured bone? Which bone did you break?" Questionnaire response choices included: hip, upper leg (not hip), pelvis, knee (patella), lower leg or ankle, foot (not toe), spine or back (vertebra), lower arm or wrist, hand (not finger), elbow, and upper arm or shoulder. We grouped each fracture into one of the following (mutually exclusive) categories: upper limb fracture (elbow, hand except fingers, lower arm/wrist, upper arm/humerus or shoulder), lower limb (foot except toes, knee/patella, upper leg except hip, lower leg/ ankle), central body (hip, pelvis, and spine). All hip fractures were centrally adjudicated. Because our goal was to examine incidence of fracture subsequent to a change in weight between baseline and year three, we excluded fractures that were reported before the third annual follow-up visit.

\section{Predictor variables}

The main predictor of this study was change in body weight between baseline and year three (plus/minus 90 days), operationalized in two ways. First, based on percentage change in body weight (for instance, ((weightvisit 3 - weight $\left._{\text {baseline }}\right) /$ weight $\left._{\text {baseline }}\right) \mathrm{X} 100$ ), we classified each participant's change in body weight into one of three categories: weight loss (decrease of $5 \%$ or more since the baseline examination), stable weight (change of less than $5 \%$ from baseline weight), and weight gain (increase of $5 \%$ or more since the baseline examination). We excluded data from participants who did not undergo measurement of body weight within 90 days of the year three visit. From the two Women's Health Initiative groups, we had information from 120566 participants regarding weight change (from baseline to year three) and at least one year of follow-up (after the year three visit) regarding incident fractures. After exclusion of data from participants for whom we lacked data regarding covariates (10\%), the sample size for analysis was 108709. 
Second, we examined unintentional and intentional weight loss as separate predictors of incident fracture. At the year three follow-up visit, participants were asked two yes/no questions: "In the past two years, did you lose five or more pounds [about $\geq 2.2 \mathrm{~kg}$ ] not on purpose at any time?" (unintentional weight loss) and "In the past two years, did you lose five or more pounds on purpose at any time?" (intentional weight loss). We had responses from 81652 participants regarding unintentional weight loss and 81587 participants regarding intentional weight loss.

\section{Other variables}

On baseline self assessment questionnaires, participants were asked whether they had experienced previous fracture (response choices were hip, spine/back/ vertebra, upper arm/humerus, lower arm/wrist, hand other than finger, lower leg/ankle, foot other than toe, or other). For this study, we collapsed responses to this question into a binary (yes/no) variable.

From the baseline self report questionnaires we gathered information on age, race/ethnicity, smoking, alcohol intake (non-drinker, past drinker, $<1 \mathrm{drink} /$ month, $<1$ drink/ week, 1-<7 drinks/week, $>7$ drinks/week, where one drink corresponded to 12 ounces $(240 \mathrm{ml})$ of beer, 6 ounces $(170 \mathrm{ml})$ of wine, or 1.5 ounces $(43 \mathrm{ml})$ of liquor), general health status ("in general, would you say your health is excellent, very good, good, fair, poor?"), number of falls to the ground during the past 12 months (none, once, twice, three times or more), oophorectomy or hysterectomy, recreational physical activity (total MET (metabolic equivalent) hours a week), energy expenditure from walking (MET hours a week), Rand 36-item health survey (SF-36) quality of life physical functioning score (range 0-100), comorbidity (modified Charlson index score ${ }^{13}$ ), previous diagnosis of cancer, average protein intake from foods and beverages (g/day), ${ }^{14}$ dietary ${ }^{14}$ and supplemental calcium intake (mg/day), and dietary ${ }^{14}$ and supplemental vitamin D intake (IU/day).

Information regarding current use of menopausal hormone therapy, daily oral corticosteroid use, baseline use of drugs for osteoporosis (bisphosphonates, selective estrogen receptor modulators, calcitonin, parathyroid hormone, denosumab), and use of oral or injectable drugs for the treatment of diabetes (thiazolidinediones, dipeptidyl peptidase-4 inhibitors, meglitinides, glucagon-like peptide-1 agonists, insulin injection, amylin analog, sulfonylureas, biguanides, and alpha-glucosidase inhibitors) was assessed at baseline by clinic staff who examined labels of drug containers.

\section{Statistical analysis}

We used Cox proportional hazards regression ${ }^{15}$ to determine the association between weight change between baseline and the third annual follow-up visit and time to first fracture after the third annual follow-up visit, using individual regression models for each anatomical fracture location: central body (hip, pelvis, spine), lower extremity (upper leg except hip, knee/patella, lower leg/ankle, foot except toe), and upper extremity (upper arm/humerus, shoulder, lower arm/wrist, hand except finger, elbow). Fractures during the first three years of follow-up were excluded from this analysis. Among women who experienced fracture, duration of follow-up was defined as time to first fracture. Among women who did not experience fracture during follow-up, duration of follow-up was defined as time until last follow-up visit, or death, whichever came first. The main predictors (in separate regression models) were category of (measured) weight change (stable, weight loss, weight gain); self reported intentional weight loss of $\geq 2.2 \mathrm{~kg}$ in the two years preceding the year three follow-up visit (yes $v$ no [reference]); and self reported unintentional weight loss (yes $v$ no [reference]) of $\geq 2.2 \mathrm{~kg}$ in the two years before the year three follow-up visit.

Covariates included baseline height, baseline weight, age, race, smoking (current, never, past), alcohol intake, general health status, number of falls in the 12 months before baseline, oophorectomy, hysterectomy, recreational physical activity (MET hours/week), physical function score, comorbidity (Charlson index) score, baseline dietary and supplemental vitamin D intake, baseline dietary and supplemental calcium intake, use of menopausal hormone therapy at baseline, daily use of oral corticosteroids at baseline, use of oral or injectable diabetes drugs at baseline, study cohort (participation in the Women's Health Initiative Observational Study), previous fracture, and previous diagnosis of cancer (yes/no). To explore the influence of protein intake and walking on the associations of weight loss with risk of fracture, we added dietary protein intake (g/ day) and energy expenditure from walking in kcal/ week/kg (MET hours a week). Continuous predictors were handled as if linear, with the exception of vitamin D and calcium intake, which were categorized $(<200$, $200-<400,400-<600$, and $\geq 600$ IU/day for vitamin D and $<800,800-<1200$, or $\geq 1200 \mathrm{mg} /$ day for calcium).

We tested the assumption that the hazard ratio of the primary predictor remained constant over time by introducing a cross product term for Î" weight ${ }^{\star} \log$ (time) into the statistical model. The proportionality assumption was not violated.

We made the a priori decision to determine whether race/ethnicity, age category, and number of falls in the past 12 months (none, once, twice, three or more times) modified the associations between change in weight and incidence of fracture by including interaction terms in regression models. Race/ethnicity categories for interaction testing were white, black, Hispanic, Asian/Pacific Islander, and other. Age categories for interaction testing were $<50-59,60-69$, and $\geq 70$. We also examined whether associations between change in weight and fracture incidence varied by physical activity level (continuous, or binary above $v$ below median), physical function level (continuous, or binary above $v$ below median), and waist:hip ratio $\left(\geq 0.9 v<0.9^{16}\right)$

We also examined the results stratified by category of baseline BMI (<24.9, 25.0-29.9, >29.9) because previous studies suggest that associations between weight 
change and incident fracture could vary according to baseline BMI. ${ }^{5} 6$

Because participants in the Women's Health Initiative Dietary Modification Trial could have had weight change patterns that were different from those of the remainder of the analytic sample, we performed a sensitivity analysis in which we restricted the analytic sample to participants in that trial (samples sizes of 34050 for lower limb fracture, 34089 for upper limb fracture, 34657 for central body fracture, and 34851 for hip fracture analyses). In another sensitivity analysis, we excluded data from participants who reported the use of drugs for osteoporosis at baseline. In the final sensitivity analysis, we used the following alternative categories of weight change: stable weight $(<5 \%$ change, reference), weight gain $5 \%-<10 \%$, weight gain $\geq 10 \%$, weight loss $5 \%-<10 \%$, and weight loss $\geq 10 \%$.

Statistical analyses were performed with SAS 9.3 (SAS Institute, Cary, NC).

\section{Results}

The mean age of our study population was 63.3 (median 63, interquartile range 58-69) (table 1). Sixteen percent of participants were non-white (Table 2). At baseline, fewer than $10 \%$ of participants were current smokers (table 2) and about 30\% had fallen at least once in the past 12 months (table 3). Among the weight change groups, the mean duration of follow-up for incident fractures ranged from 11.5-12.0 years from baseline.

figure 2 shows the distribution of annualized weight change. Mean annualized percentage change in measured body weight was $0.30 \%$ /year overall $(-3.6 \%$ /year in the weight loss group $\mathrm{n}=18266,0.09 \% /$ year in the stable weight group $n=79279$, and 4.1\%/year in the weight gain group $n=23021$ ). Mean weight change (from baseline to year three) was $-10.0 \mathrm{~kg}$ (SD $15.0 \mathrm{~kg}$ ) in the weight loss group and $8.7 \mathrm{~kg}$ (SD $13.4 \mathrm{~kg}$ ) in the weight gain group. Of the participants who responded to questions regarding unintentional $(n=62185)$ and intentional ( $n=62142)$ weight loss ( $2.2 \mathrm{~kg}$ in the past two years), 27530 (44\%) reported intentional weight loss, and 14653 (24\%) of participants reported unintentional weight loss.

Table 1 Mean (SD) baseline characteristics of participants from Women's Health Initiative Observational Study and Women's Health Initiative Clinical Trials included in analytic sample* in study of effect of postmenopausal weight change on risk of fracture

\begin{tabular}{|c|c|c|c|}
\hline Variable & $\begin{array}{l}\text { Stable weight } \\
(n=79279)\end{array}$ & $\begin{array}{l}\text { Weight loss } \\
(n=18266)\end{array}$ & $\begin{array}{l}\text { Weight gain } \\
(n=23021)\end{array}$ \\
\hline Age (years) & $63.5(7.1)$ & $64.2(7.3)$ & $61.5(7.0)$ \\
\hline Weight (kg) & $72.1(15.2)$ & $78.9(21.8)$ & $71.6(14.9)$ \\
\hline Height (m) & $161.8(6.5)$ & $161.4(7.2)$ & $162.0(6.7)$ \\
\hline Years since menopause & 15.2(9.1) & $16.0(9.4)$ & $13.6(9.0)$ \\
\hline Waist (cm) & $85.5(13.4)$ & $89.1(14.2)$ & $85.1(13.2)$ \\
\hline Waist/hip ratio & $0.8(0.1)$ & $0.8(0.1)$ & $0.8(0.1)$ \\
\hline Physical activity (MET hours/week) & $12.9(13.8)$ & $11.1(12.8)$ & $12.5(13.8)$ \\
\hline Physical functioning & $82.8(18.4)$ & $78.2(21.1)$ & $82.4(19.3)$ \\
\hline Comorbidity & $0.99(1.1)$ & $1.11(1.1)$ & $0.98(1.1)$ \\
\hline Age (years) at menopause & $48.3(6.3)$ & $48.1(6.5)$ & $47.9(6.4)$ \\
\hline $\begin{array}{l}\text { Mean }(95 \% \mathrm{Cl}) \text { annualized percent } \\
\text { weight change }\end{array}$ & 0.09 (0.27 to 0.31) & $-3.67(-3.71$ to -3.62$)$ & $4.1(4.07$ to 4.25$)$ \\
\hline
\end{tabular}

Characteristics of the analytic sample were similar to those of excluded participants except that, compared with the excluded participants, the participants in the analytic sample were more likely to be participants in the clinical trial (47\% v 26\%) and were more likely to be white (84\% v 78\%) (data not shown).

\section{Adjusted associations between annualized} percentage weight change and incidence of fracture Associations between category of weight change ( $\geq 5 \%$ weight loss, $\geq 5 \%$ weight gain, stable weight) and incidence of fracture were adjusted for baseline age, race, baseline height, baseline weight, smoking, alcohol intake, total energy expended a week, baseline vitamin D intake, baseline calcium intake, physical function score, general health status, oophorectomy, hysterectomy, Charlson index score, use of menopausal hormone therapy, daily oral corticosteroid use, use of oral or injectable treatment for diabetes, study assignment (Women's Health Initiative Observational Study, Women's Health Initiative Clinical Trials), history of previous fracture, and previous diagnosis of cancer (Table 4). Compared with women who had stable weight between baseline and the third annual visit, women who lost weight had a $9 \%$ higher incidence of upper limb fracture (adjusted hazard ratio 1.09, 95\% confidence interval 1.03 to 1.16), a 30\% higher incidence of central body fracture (1.30, 1.22 to 1.39), and 65\% higher incidence of hip fracture (1.65, 1.49 to 1.82). Compared with women who had stable weight, women who gained weight had a 10\% higher incidence of upper limb fracture (1.10, 1.04 to 1.17 ) and an $18 \%$ higher incidence of lower limb fracture $(1.18,1.12$ to 1.25$)$. The addition of a covariate representing the number of falls in past 12 months did not notably alter the hazard ratios for the associations between weight change and fracture incidence. Similarly, further adjustment for weekly energy expenditure from walking, weekly energy expenditure from recreational activity, use of antidepressant drugs, and total protein intake did not notably alter the hazard ratios for the associations between weight change and incidence of fracture (data not shown).

When we restricted the analytic sample to participants in the Women's Health Initiative Dietary Modification Trial, results were similar to results in the overall analytic sample (data not shown).

\section{Adjusted associations between intentional and} unintentional weight loss and fracture incidence

We examined associations of self reported unintentional and intentional weight loss in the past two years with incidence of fracture (see table $\mathrm{A}$ in appendix). Compared with no unintentional weight loss, unintentional weight loss was associated with a $21 \%$ higher incidence of central body fracture (adjusted hazard ratio $1.21,95 \%$ confidence interval 1.13 to 1.29 ), $33 \%$ higher incidence of hip fracture $(1.33,1.19$ to 1.47$)$, and $16 \%$ higher incidence of vertebral fracture $(1.16,1.06$ to 1.26). Compared with stable weight, intentional weight loss was associated with increased incidence rates of lower limb fracture $(1.11,1.05$ to 1.17$)$ and decreased 
Table 2 | Baseline sociodemographic characteristics of participants from Women's Health Initiative Observational Study and Women's Health Initiative Clinical Trials included in analytic sample* in study of effect of postmenopausal weight change on risk of fracture. Figures are numbers (percentage) of participants

\begin{tabular}{|c|c|c|c|c|}
\hline Variable & $\begin{array}{l}\text { Stable weight } \\
(n=79 \text { 279) }\end{array}$ & $\begin{array}{l}\text { Weight loss } \\
(\mathrm{n}=18 \text { 266) }\end{array}$ & $\begin{array}{l}\text { Weight gain } \\
(n=23021)\end{array}$ & Total \\
\hline \multicolumn{5}{|c|}{ Participant in Women's Health Initiative Clinical Trial: } \\
\hline Yes & $42528(54)$ & $8758(48)$ & $12147(53)$ & $63433(53)$ \\
\hline No & $36751(46)$ & $9508(52)$ & $10874(47)$ & $57133(47)$ \\
\hline Total & 79279 & 1866 & 23021 & 120566 \\
\hline \multicolumn{5}{|l|}{ Age (years) at screening: } \\
\hline$<50-59+$ & $24221(31)$ & $5119(28)$ & $9670(42)$ & $39010(32)$ \\
\hline $60-69$ & $37063(47)$ & $8279(45)$ & $9898(43)$ & $55240(46)$ \\
\hline$\geq 70$ & $17995(23)$ & $4868(27)$ & $3453(15)$ & $26316(22)$ \\
\hline Total & 79279 & 18266 & 23021 & 120566 \\
\hline \multicolumn{5}{|c|}{ Race/ethnicity (missing = 280): } \\
\hline White & $66915(85)$ & $15534(85)$ & $19124(83)$ & $101573(84)$ \\
\hline Black & $6045(8)$ & $1494(8)$ & $2000(9)$ & $9539(8)$ \\
\hline Hispanic & $2639(3)$ & $554(3)$ & 865 (4) & $4058(3)$ \\
\hline Asian/Pacific Islander & $2390(3)$ & $382(2)$ & $603(3)$ & $3375(3)$ \\
\hline Other & $1095(1)$ & $264(1)$ & $382(2)$ & $1741(2)$ \\
\hline Total & 79084 & 18228 & 22974 & 120286 \\
\hline \multicolumn{5}{|l|}{ Smoking $($ missing $=1377)$ : } \\
\hline Never smoked & $41695(53)$ & $9272(51)$ & $11193(49)$ & $62160(52)$ \\
\hline Past smoker & $32517(41)$ & $7509(42)$ & $9512(42)$ & $49538(42)$ \\
\hline Current smoker & $4194(5)$ & $1248(7)$ & $2053(9)$ & $7495(6)$ \\
\hline Total & 78406 & 18029 & 22758 & 119193 \\
\hline \multicolumn{5}{|c|}{ Alcohol intake (missing = 381): } \\
\hline Non-drinker & $8402(11)$ & $2105(12)$ & $2348(10)$ & $12855(11)$ \\
\hline Past drinker & $13259(17)$ & $3571(20)$ & $4478(20)$ & $21308(18)$ \\
\hline$<1$ drink/month & $9521(12)$ & $2298(13)$ & $3083(13)$ & $14902(12)$ \\
\hline$<1$ drink/week & $16243(21)$ & $3586(20)$ & $4901(21)$ & $24730(21)$ \\
\hline $1-<7$ drinks/week & $21465(27)$ & $4387(24)$ & $5716(25)$ & $31568(26)$ \\
\hline$\geq 7$ drinks/week & $9887(13)$ & $2171(12)$ & $2359(10)$ & $14417(12)$ \\
\hline Total & 79048 & 18186 & 22951 & 120185 \\
\hline \multicolumn{5}{|l|}{ BMI (missing = 220): } \\
\hline Underweight $(<18.5)$ & $626(1)$ & $97(1)$ & $298(1)$ & $1021(1)$ \\
\hline Normal (18.5-24.9) & $29207(37)$ & $4506(25)$ & $8550(37)$ & $42263(35)$ \\
\hline Overweight (25.0-29.9) & $27544(35)$ & $6312(35)$ & $8243(36)$ & $42099(35)$ \\
\hline Obesity I (30.0-34.9) & $14093(18)$ & $4010(22)$ & $3889(17)$ & $21992(18)$ \\
\hline Obesity II (35.0-39.9) & $5461(7)$ & $1817(10)$ & $1397(6)$ & $8675(7)$ \\
\hline Extreme obesity III $(\geq 40)$ & $2478(3)$ & $1165(7)$ & $653(3)$ & $4296(4)$ \\
\hline Total & 79409 & 17907 & 23030 & 120346 \\
\hline
\end{tabular}

${ }^{*}$ All $\mathrm{P}<0.001$ for difference between weight groups.

tFive participants were aged 49 at enrollment in Women's Health Initiative.

incidence of central body fracture $(0.93,0.88$ to 0.99$)$ and hip fractures $(0.85,0.76$ to 0.95$)$.

Interaction tests: associations between weight change and fracture incidence according to baseline BMI, frequency of falls, age, race/ethnicity, diabetes, physical activity, physical function, and waist:hip ratio Associations of intentional and unintentional weight loss did not vary by age group, with one exception: associations between intentional weight loss and lower limb fracture were more pronounced in younger than in older women ( $\mathrm{P}=0.008$ for interaction). Among women aged $50-59$, those with intentional weight loss had a $25 \%$ higher risk of lower limb fracture than women without intentional weight loss (see table B in appendix).

Associations between weight change and incidence of fracture did not significantly differ by baseline BMI category, number of falls in the past 12 months, race/ ethnicity, presence or absence of diabetes mellitus at baseline, physical activity levels, and physical function levels (for upper limb, lower limb, and central body fractures all $\mathrm{P}>0.05$ for interaction).

Among women who gained weight, associations between weight gain and fracture did not differ by waist:hip ratio $(>0.9 v \leq 0.9)$.

\section{Sensitivity analyses}

We performed a sensitivity analysis in which we added extra categories of weight change. We used the following categories: stable weight $(<5 \%$ change, reference), weight gain $5 \%-<10 \%$, weight gain $\geq 10 \%$, weight loss $5 \%-<10 \%$, and weight loss $\geq 10 \%$. The pattern of results was similar to those of the primary analyses (Table 5).

For all analyses, results were similar when we excluded data from participants who reported the use of drugs for osteoporosis at baseline (data not shown).

\section{Discussion \\ Principal findings}

In this large cohort of postmenopausal women, compared with women with stable weight over three years, women who had lost $5 \%$ or more of their body weight had about $65 \%$ higher incidence rates of hip fracture, $30 \%$ higher rates of central body fracture, and $9 \%$ higher rates of upper limb fracture over about 11 years of follow-up. Also, compared with women who had stable weight, women who had weight gain of $5 \%$ or more had 10\% higher incidence rates of upper and $18 \%$ higher rates of lower limb fractures but no difference in central body fractures. These associations were not explained by baseline frequency of falls or diagnosis of cancer before the third year of follow-up. Compared with stable weight, unintentional weight loss was associated with an increased risk of hip and spine fractures, whereas intentional weight loss was associated with a decreased risk of hip fractures and increased risk of lower limb fractures.

\section{Comparison with other studies}

As far as we are aware, this study is the first longitudinal study to focus specifically on how weight change can differentially influence upper limb, lower limb, and central body fractures among postmenopausal women in the US. The associations that we found between weight loss and increased rates of hip fracture, however, agree with those of previous studies. In a previous study of white women aged $\geq 65$, weight loss over four years of follow-up was associated with an increased risk of hip fracture. ${ }^{4} \mathrm{Simi}-$ larly, self reported weight loss of $\geq 10 \%$ of body weight since age 50 among white women aged 67 and older ${ }^{5}$ and self reported weight loss of $\geq 10 \%$ from maximum weight among white women aged $50-74^{6}$ were each associated with an increased risk of hip fracture. Our results were also consistent with those of a previous study in which weight gain since age 25 was associated with a higher risk of ankle fracture among white women aged $\geq 65$. ${ }^{9}$ Finally, our results are consistent with results of studies from other countries-for example, Norwegian cohort 
Table 3 | Baseline clinical and health related characteristics of participants from Women's Health Initiative Observational Study and Women's Health Initiative Clinical Trials included in analytic sample* in study of effect of postmenopausal weight change on risk of fracture. Figures are numbers (percentage) of participants

\begin{tabular}{|c|c|c|c|c|}
\hline Variable & $\begin{array}{l}\text { Stable weight } \\
(\mathrm{n}=79279)\end{array}$ & $\begin{array}{l}\text { Weight loss } \\
(n=18266)\end{array}$ & $\begin{array}{l}\text { Weight gain } \\
(n=23021)\end{array}$ & Total \\
\hline \multicolumn{5}{|c|}{ Daily oral corticosteroid use: } \\
\hline No & $77889(98)$ & $17743(97)$ & $22531(98)$ & $118163(98)$ \\
\hline Yes & $1390(2)$ & $523(3)$ & $490(2)$ & $2403(2)$ \\
\hline Total & 79279 & 18266 & 23021 & 120566 \\
\hline \multicolumn{5}{|c|}{ Dietary + supplemental calcium (mg/day): } \\
\hline$<800$ & $26648(34)$ & $6359(35)$ & $8123(35)$ & $41130(34)$ \\
\hline $800-<1200$ & $19670(25)$ & $4535(25)$ & $5516(24)$ & $29721(25)$ \\
\hline$\geq 1200$ & $32961(42)$ & $7372(40)$ & $9382(41)$ & $49715(41)$ \\
\hline Total & 79279 & 18266 & 23021 & 120566 \\
\hline \multicolumn{5}{|c|}{ Dietary + supplemental vitamin D (IU/day): } \\
\hline$<200$ & $29223(37)$ & $6879(38)$ & $8735(38)$ & $44837(37)$ \\
\hline $200-<400$ & $14906(19)$ & 3459 (19) & $3994(17)$ & 22359 (19) \\
\hline $400-<600$ & $19563(25)$ & $4486(25)$ & $5873(26)$ & $29922(29)$ \\
\hline$\geq 600$ & $15587(20)$ & $3442(19)$ & 4419 (19) & $23448(20)$ \\
\hline Total & 79279 & 18266 & 23021 & 120566 \\
\hline \multicolumn{5}{|l|}{ Arthritis: } \\
\hline Rheumatoid arthritis & $3504(4)$ & $972(5)$ & $1053(5)$ & $115037(95)$ \\
\hline Other/don't know & $75775(96)$ & $17294(95)$ & $21968(95)$ & $5529(5)$ \\
\hline Total & 79279 & 18266 & 23021 & 120566 \\
\hline \multicolumn{5}{|c|}{ Diabetes treatment (oral or injectable) (missing = 95): } \\
\hline No & $76457(97)$ & $17266(95)$ & $22109(96)$ & $115832(96)$ \\
\hline Yes & $2756(3)$ & $987(5)$ & $896(4)$ & $4639(4)$ \\
\hline Total & 79213 & 18253 & 23005 & 120471 \\
\hline \multicolumn{5}{|c|}{ Bilateral oophorectomy (missing = 2594): } \\
\hline No & $62361(80)$ & $14240(80)$ & $18170(81)$ & $94771(80)$ \\
\hline Yes & $15264(20)$ & $3583(20)$ & $4354(19)$ & $23201(20)$ \\
\hline Total & 77625 & 17823 & 22524 & 117972 \\
\hline \multicolumn{5}{|c|}{ Hysterectomy (missing = 52): } \\
\hline No & $46539(59)$ & $10678(58)$ & $13483(59)$ & $70700(59)$ \\
\hline Yes & $32699(41)$ & $7583(42)$ & $9532(41)$ & $49814(41)$ \\
\hline Total & 79238 & 18261 & 23015 & 120514 \\
\hline \multicolumn{5}{|c|}{ Menopausal hormone therapy use (missing = 88): } \\
\hline Never used & $33992(43)$ & $8420(46)$ & $9451(41)$ & $51863(43)$ \\
\hline Past user & $12757(16)$ & $2995(16)$ & $3644(16)$ & $19396(16)$ \\
\hline Current user & $32472(41)$ & $6838(37)$ & 9909 (43) & $49219(41)$ \\
\hline Total & 79221 & 18253 & 23004 & 120478 \\
\hline \multicolumn{5}{|c|}{ Self rated general health status (missing $=663$ ): } \\
\hline Excellent & $14639(19)$ & $2618(14)$ & 4109 (18) & $21366(18)$ \\
\hline Very good & $34123(43)$ & $7272(40)$ & $9570(42)$ & $50965(42)$ \\
\hline Good & $24667(31)$ & $6470(36)$ & $7310(32)$ & $38447(32)$ \\
\hline Fair & $5104(6)$ & $1629(9)$ & $1746(8)$ & $8479(7)$ \\
\hline Poor & $323(0)$ & $159(1)$ & $164(1)$ & $646(1)$ \\
\hline Total & 78856 & 18148 & 22899 & 119903 \\
\hline \multicolumn{5}{|c|}{ No of falls in past 12 months (missing $=5271$ ): } \\
\hline None & $51686(68)$ & $11334(65)$ & $14753(67)$ & $77773(67)$ \\
\hline 1 & $15255(20)$ & $3608(21)$ & $4448(20)$ & $23311(21)$ \\
\hline 2 & $6046(8)$ & $1567(9)$ & $1886(9)$ & $9499(8)$ \\
\hline$\geq 3$ & $2886(4)$ & $827(5)$ & $999(5)$ & $4712(4)$ \\
\hline Total & 75873 & 17336 & 22086 & 115295 \\
\hline
\end{tabular}

studies that found associations between weight loss and an increased risk of distal forearm fractures ${ }^{17}$ and non-vertebral fractures ${ }^{18}$ in women.

Although our study focused on change in body weight and incidence of fracture, a previous Women's Health Initiative study examined the differential effects

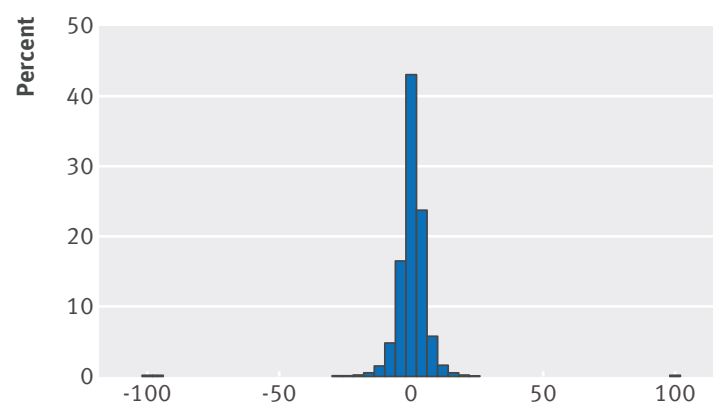

Change in body weight (kg) (baseline to visit 3)

Fig 2. | Histogram of distribution of annualized weight change

of baseline weight on fractures at various anatomical locations. ${ }^{19}$ In that study, higher baseline BMI was associated with a decreased incidence of hip fractures and central body fractures, whereas the risk of upper extremity fracture was independent of baseline BMI. The authors of that study postulated that the greater soft tissue padding of the hip and central body could counteract the higher traumatic forces that accompany higher body weight. The results of our study possibly support that hypothesis, in that weight gain was not associated with an increased risk of hip fracture but was associated with an increased incidence of upper and lower limb fractures, anatomical sites that have less soft tissue padding.

Serious illness can be an underlying cause of both involuntary weight loss and osteoporosis. The associations that we found between weight loss and incidence of fracture persisted after adjustment for a diagnosis of cancer and other comorbidities. Also, in the current study, only unintentional, not intentional, weight loss was associated with an increased risk of hip fracture. Previous studies regarding voluntary weight loss and risk of fracture have focused on non-vertebral or overall frailty fractures rather than fractures according to specific anatomical regions. ${ }^{320}$ In one study, however, voluntary and involuntary weight loss among overweight women were each associated with similar (2.5-fold) increases in risk of hip fracture. ${ }^{4}$ Compared with the participants of the previous study, participants of the Women's Health Initiative were younger at baseline and probably generally healthier.

\section{Strengths and limitations}

Strengths of our study include its long duration of follow-up, detailed information regarding risk factors for fracture, objective measurement of body weight (as opposed to self reported body weight), and large sample size including more than 18000 non-white women (9539 black women) and nearly 40000 younger postmenopausal women (aged 50-59 at baseline) who were not the focus of previous studies. ${ }^{34}$

Our study has potential limitations. Although we used adjudicated information regarding hip fractures, information regarding other fractures was self reported. The validity of self report of fractures varies by anatomical site in Women's Health Initiative, being higher for hip (78\%) and forearm/wrist (81\%) fractures than for 
Table 4 | Association between postmenopausal change in body weight (third annual follow-up visit minus baseline) and incidence of fracture in Women's Health Initiative Observational Study and Women's Health Initiative Clinical Trials according to fracture site, before and after adjustment for falls*. Figures are adjusted hazard ratiost ( $95 \%$ confidence interval)

\begin{tabular}{|c|c|c|}
\hline $\begin{array}{l}\text { Fracture site and weight change } \\
\text { category }\end{array}$ & Model 1 & $\begin{array}{l}\text { Model } 1+\text { No of falls past } \\
12 \text { months }\end{array}$ \\
\hline \multicolumn{3}{|l|}{ Upper limb‡ } \\
\hline Stable weight (reference) & 1.00 & 1.00 \\
\hline Weight loss & 1.09 (1.03 to 1.16$)$ & $1.08(1.02$ to 1.15$)$ \\
\hline Weight gain & 1.10 (1.04 to 1.17$)$ & 1.09 (1.04 to 1.16$)$ \\
\hline \multicolumn{3}{|l|}{ Lower limb§ } \\
\hline Stable weight (reference) & 1.00 & 1.00 \\
\hline Weight loss & 0.98 (0.92 to 1.05$)$ & $0.98(0.92$ to 1.04$)$ \\
\hline Weight gain & 1.18 (1.12 to 1.25$)$ & 1.18 (1.11 to 1.24$)$ \\
\hline \multicolumn{3}{|l|}{ Central bodyף } \\
\hline Stable weight (reference) & 1.00 & 1.00 \\
\hline Weight loss & 1.30 (1.22 to 1.39$)$ & 1.30 (1.21 to 1.38$)$ \\
\hline Weight gain & 0.96 (0.90 to 1.03$)$ & 0.96 (0.90 to 1.03$)$ \\
\hline \multicolumn{3}{|l|}{ Hip } \\
\hline Stable weight (reference) & 1.00 & 1.00 \\
\hline Weight loss & 1.65 (1.49 to 1.82$)$ & 1.64 (1.49 to 1.82$)$ \\
\hline Weight gain & 0.96 (0.86 to 1.08$)$ & 0.96 (0.86 to 1.08$)$ \\
\hline \multicolumn{3}{|c|}{$\begin{array}{l}\text { *Sample sizes with complete covariate information according to fracture site were: } 106113 \text { for lower limb } \\
\text { fracture, } 106286 \text { for upper limb fracture, } 108003 \text { for central body fracture, and } 108709 \text { for hip fracture } \\
\text { analyses. Over follow-up period, } 8531 \text { upper limb fractures, } 8529 \text { lower limb fractures, } 6791 \text { central body } \\
\text { fractures, and } 2436 \text { hip fractures occurred in analytic sample. } \\
\text { †Adjusted for baseline age, race, height, baseline weight, smoking, alcohol intake, total energy expended per } \\
\text { week, dietary and supplemental vitamin D intake, dietary and supplemental calcium intake, physical function } \\
\text { score, general health status, oophorectomy, hysterectomy, Charlson index score, use of menopausal hormone } \\
\text { therapy, daily oral corticosteroid use, use of oral or injectable diabetes medication, study group (Women's } \\
\text { Health Initiative Observational Study, Women's Health Initiative Clinical Trials group assignment), previous } \\
\text { diagnosis of cancer, and previous fracture. } \\
\text { Includes fractures of upper arm/humerus, shoulder, lower arm/wrist, hand (except finger), and elbow. } \\
\text { Includes fractures of upper leg (except hip), knee/patella, lower leg/ankle, and foot (except toe). } \\
\text { Includes fractures of hip, pelvis, and spine. }\end{array}$} \\
\hline
\end{tabular}

Table 5 | Sensitivity analysis: associations between body weight change (third annual follow-up visit minus baseline) and incidence of fracture by site in Women's Health Initiative Observational Study and Women's Health Initiative Clinical Trials according to anatomical location, with additional weight change categories.*

\begin{tabular}{lllll}
$\begin{array}{l}\text { Weight change } \\
\text { category }\end{array}$ & Upper limb & Lower limb & Central body & Hip \\
$\begin{array}{l}\text { Stable weight } \\
\text { (reference) }\end{array}$ & 1.00 & 1.00 & 1.00 & 1.00 \\
\hline $\begin{array}{l}\text { Weight loss } \\
5 \%-\leq 10 \%\end{array}$ & $1.07(1.00$ to 1.15$)$ & $0.96(0.89$ to 1.03$)$ & $1.27(1.18$ to 1.37$)$ & $1.53(1.36$ to 1.72$)$ \\
\hline Weight loss $>10 \%$ & $1.13(1.03$ to 1.25$)$ & $1.03(0.93$ to 1.14$)$ & $1.35(1.22$ to 1.50$)$ & $1.87(1.61$ to 2.17$)$ \\
\hline $\begin{array}{l}\text { Weight gain } \\
5 \%-\leq 10 \%\end{array}$ & $1.11(1.05$ to 1.19$)$ & $1.18(1.11$ to 1.25$)$ & $0.96(0.89$ to 1.04$)$ & $0.93(0.81$ to 1.06$)$ \\
\hline
\end{tabular}

\begin{tabular}{lllll}
\hline Weight gain $\geq 10 \%$ & 1.08 (0.98 to 1.18$)$ & $1.18(1.08$ to 1.29$)$ & $0.98(0.87$ to 1.09$)$ & 1.08 (0.90 to 1.31$)$
\end{tabular}

*Adjusted for baseline age, race, height, baseline weight, smoking, alcohol intake, total energy expended per week, dietary and supplemental vitamin D intake, dietary and supplemental calcium intake, physical function score, general health status, oophorectomy, hysterectomy, Charlson index score, use of menopausal hormone therapy, daily oral corticosteroid use, use of oral or injectable diabetes medication, study group (Women's Health Initiative Observational Study, Women's Health Initiative Clinical Trials), previous diagnosis of cancer, and previous fracture. Includes fractures of upper arm/humerus, shoulder, lower arm/wrist, hand (except finger), and elbow. Includes fractures of upper leg (except hip), knee/patella, lower leg/ankle, and foot (except toe). Includes fractures of hip, pelvis, and spine.

clinical spine fractures (51\%). ${ }^{21}$ We did not have information regarding circumstances of the fracture (such as specific activities that immediately preceded fractures). To examine associations between weight change and subsequent incident fractures, we examined associations between change in weight from baseline to the third annual follow-up visit in relation to incident fractures subsequent to the third annual follow-up visit.
Participants might, however, have experienced weight change during the fracture follow-up period. Finally, we did not adjust for multiple statistical comparisons, so the probability that at least one of the reported confidence intervals will exclude unity under an overall null hypothesis is greater than 0.05 .

\section{Conclusions and policy implications}

In conclusion, our finding that weight gain $(\geq 5 \%$ of body weight over three years) is associated with increased incidence rates of upper and lower limb fractures is a novel finding. We found that weight loss ( $\geq 5 \%$ of body weight over three years) is associated with a markedly increased rate of hip fracture, as well as increased rates of central body and upper limb fractures, compared with stable weight. These findings have clinical and research implications and challenge the traditional clinical paradigm of weight gain protecting against fractures. Clinicians should be aware that even intentional weight loss is associated with increased rates of lower limb fractures. Weight loss intervention trials should consider potential effects on the incidence of fracture.

This is an Open Access article distributed in accordance with the Creative Commons Attribution Non Commercial (CC BY-NC 4.0) license, which permits others to distribute, remix, adapt, build upon this work non-commercially, and license their derivative works on different terms, provided the original work is properly cited and the use is noncommercial. See: http://creativecommons.org/licenses/by-nc/4.0/.

We thank the women who generously participated in the Women's Health Initiative and the Women's Health Initiative investigators and staff for their dedicated efforts.

Program office: (National Heart, Lung, and Blood Institute, Bethesda, Maryland) Jacques Rossouw, Shari Ludlam, Dale Burwen, Joan McGowan, Leslie Ford, Nancy Geller.

Clinical coordinating center: (Fred Hutchinson Cancer Research Center, Seattle, WA) Garnet Anderson, Ross Prentice, Andrea LaCroix, Charles Kooperberg, Barbara Cochrane, Julie Hunt, Marian Neuhouser, Lesley Tinker, Susan Heckbert, Alex Reiner.

Regional centers: (Brigham and Women's Hospital, Harvard Medical School, Boston, MA) JoAnn E Manson, Kathryn M Rexrode, Brian Walsh, J Michael Gaziano, Maria Bueche; (MedStar Health Research Institute/Howard University, Washington, DC) Barbara V Howard, Lucile Adams-Campbell, Lawrence Lessin, Cheryl Iglesia, Brian Walitt, Amy Park; (Ohio State University, Columbus, $\mathrm{OH}$ ) Rebecca Jackson, Randall Harris, Electra Paskett, W Jerry Mysiw, Michael Blumenfeld; (Stanford Prevention Research Center, Stanford, CA) Marcia L Stefanick, Mark A Hlatky, Manisha Desai, Jean Tang, Stacy T Sims; (University of Arizona, Tucson/Phoenix, AZ) Cynthia A Thomson, Tamsen Bassford, Cheryl Ritenbaugh, Zhao Chen, Marcia Ko; (University at Buffalo, Buffalo, NY) Jean Wactawski-Wende, Maurizio Trevisan, Ellen Smit, Amy Millen, Michael LaMonte; (University of Florida, Gainesville/Jacksonville, FL) Marian Limacher, Michael Perri, Andrew Kaunitz, R Stan Williams, Yvonne Brinson; (University of lowa, Iowa City/Davenport, IA) Robert Wallace, James Torner, Susan Johnson, Linda Snetselaar, Jennifer Robinson; (University of Pittsburgh, Pittsburgh, PA) Lewis Kuller, Jane Cauley, N Carole Milas; (University of Tennessee Health Science Center, Memphis, TN) Karen C Johnson, Suzanne Satterfield, Rongling Li, Stephanie Connelly, Fran Tylavsky; (Wake Forest University School of Medicine, Winston-Salem, NC) Sally Shumaker, Stephen Rapp, Claudine Legault, Mark Espeland, Laura Coker, Michelle Naughton.

Women's Health Initiative Memory Study: (Wake Forest University School of Medicine, Winston-Salem, NC) Sally Shumaker, Stephen Rapp, Claudine Legault, Mark Espeland, Laura Coker, Michelle Naughton.

Former principal investigators and project officers: (Albert Einstein College of Medicine, Bronx, NY) Sylvia Wassertheil-Smoller; (Baylor College of Medicine, Houston, TX) Haleh Sangi-Haghpeykar, Aleksandar Rajkovic, Jennifer Hays, John Foreyt; (Brown University, 
Providence, RI) Charles B Eaton, Annlouise R Assaf; (Emory University, Atlanta, GA) Lawrence S Phillips, Nelson Watts, Sally McNagny, Dallas Hall; (Fred Hutchinson Cancer Research Center, Seattle, WA) Shirley A A Beresford, Maureen Henderson; (George Washington University, Washington, DC) Lisa Martin, Judith Hsia, Valery Miller; (Harbor-UCLA Research and Education Institute, Torrance, CA) Rowan Chlebowski; (Kaiser Permanente Center for Health Research, Portland, OR) Erin LeBlanc, Yvonne Michael, Evelyn Whitlock, Cheryl Ritenbaugh, Barbara Valanis; (Kaiser Permanente Division of Research, Oakland, CA) Bette Caan, Robert Hiatt; (National Cancer Institute, Bethesda, MD) Carolyn Clifford; (Medical College of Wisconsin, Milwaukee, WI) Jane Morley Kotchen; (National Heart, Lung, and Blood Institute, Bethesda, Maryland) Linda Pottern; (Northwestern University, Chicago/Evanston, IL) Linda Van Horn, Philip Greenland; (Rush University Medical Center, Chicago, IL) Lynda Powell, William Elliott, Henry Black; (State University of New York at Stony Brook, Stony Brook, NY) Dorothy Lane, Iris Granek; (University at Buffalo, Buffalo, NY) Maurizio Trevisan; (University of Alabama at Birmingham, Birmingham, AL) Cora E Lewis, Albert Oberman; (University of Arizona, Tucson/Phoenix, AZ) Tamsen Bassford, Cheryl Ritenbaugh, Tom Moon; (University of California at Davis, Sacramento, CA) John Robbins; (University of California at Irvine, CA) F Allan Hubbell, Frank Meyskens Jr; (University of California at Los Angeles, CA) Lauren Nathan, Howard Judd; (University of California at San Diego, Lajolla/ Chula Vista, CA) Robert D Langer; (University of Cincinnati, Cincinnati, $\mathrm{OH}$ ) Michael Thomas, Margery Gass, James Liu; (University of Hawaii, Honolulu, HI) J David Curb; (University of Massachusetts/Fallon Clinic, Worcester, MA) Judith Ockene; (University of Medicine and Dentistry of New Jersey, Newark, N)) Norman Lasser; (University of Miami, Miami, FL) Mary Jo O'Sullivan, Marianna Baum; (University of Minnesota, Minneapolis, MN) Karen L Margolis, Richard Grimm; (University of Nevada, Reno, NV) Robert Brunner, Sandra Daugherty; (University of North Carolina, Chapel Hill, NC) Gerardo Heiss, Barbara Hulka, David Sheps; (University of Tennessee Health Science Center, Memphis, TN) Karen Johnson, William Applegate; (University of Texas Health Science Center, San Antonio, TX) Robert Brzyski, Robert Schenken; (University of Wisconsin, Madison, WI) Gloria E Sarto, Catherine Allen; (Wake Forest University School of Medicine, Winston-Salem, NC) Mara Vitolins, Denise Bonds, Electra Paskett, Greg Burke; (Wayne State University School of Medicine/Karmanos Cancer Institute, Detroit, MI) Michael S Simon, Susan Hendrix.

Contributors: CJC and JAC had the original idea and designed the study. JW-W and KCJ acquired data and obtained funding. All authors analyzed and interpreted the data. CJC drafted the manuscript and all authors critically revised it for important intellectual content. VOY carried out the statistical analysis. CJC supervised the study and is guarantor.

Funding: The WHI program is funded by the National Heart, Lung, and Blood Institute, National Institutes of Health, US Department of Health and Human Services through contracts HHSN268201100046C, HHSN268201100001C, HHSN268201100002C, HHSN268201100003C, HHSN268201100004C, and HHSN271201100004C. The funders had no role in the design and conduct of the study, the collection, analysis, and interpretation of the data, or the preparation, review, or approval of the manuscript.

Competing interests: All authors have completed the ICMJE uniform disclosure form at www.icmje.org/coi_disclosure.pdf and declare: no support from any organization for the submitted work; no financial relationships with any organizations that might have an interest in the submitted work in the previous three years; no other relationships or activities that could appear to have influenced the submitted work.

Ethical approval: The Women's Health Initiative was overseen by ethics committees at all 40 clinical centers, by the coordinating center, and by a data and safety monitoring board. Each institution obtained human subjects committee approval. Each participant provided written informed consent.

Role of sponsor: The Women's Health Initiative (WHI) project office at the National Heart, Lung, and Blood Institute (NHLBI), which was the sponsor, had a role in the design and conduct of the study and in the collection and management of the data. The sponsor did not have a role in analysis and interpretation of the data, the preparation of the manuscript, or the decision to submit the manuscript for publication. Review and approval of the manuscript was carried out by committees composed of WHI investigators and NHLBI representatives.
Transparency declaration: The lead author affirms that this manuscript is an honest, accurate, and transparent account of the study being reported; that no important aspects of the study have been omitted; and that any discrepancies from the study as planned have been explained.

Data sharing: Women's Health Initiative Study data are available via the BioLINCC website of the National Heart, Lung, and Blood Institute at https://biolincc.nhlbi.nih.gov/home/

1 US Department of Health and Human Services. Bone health and osteoporosis: a report of the Surgeon General Executive Summary. US Department of Health and Human Services, 2004.

2 Premaor MO, Pilbrow L, Tonkin C, Parker RA, Compston I. Obesity and fractures in postmenopausal women. J Bone Miner Res 2010:25:292-7.

3 Ensrud KE, Cauley J, Lipschutz R, Cummings SR. Weight change and fractures in older women. Study of Osteoporotic Fractures Research Group. Arch Intern Med 1997:157:857-63.

4 Ensrud KE, Ewing SK, Stone KL, Cauley JA, Bowman PJ, Cummings SR. Intentional and unintentional weight loss increase bone loss and hip fracture risk in older women. J Am Geriatr Soc 2003;51:1740-7.

5 Langlois JA, Harris T, Looker AC, Madans J. Weight change between age 50 years and old age is associated with risk of hip fracture in white women aged 67 years and older. Arch Intern Med 1996;156:989-94.

6 Langlois JA, Mussolino ME, Visser M, Looker AC, Harris T, Madans I. Weight loss from maximum body weight among middle-aged and older white women and the risk of hip fracture: the NHANES I epidemiologic follow-up study. Osteoporos Int 2001:12:763-8.

7 Taveras EM, Gillman MW, Kleinman KP, Rich-Edwards JW, Rifas-Shiman SL. Reducing racial/ethnic disparities in childhood obesity: the role of early life risk factors. JAMA Pediatr 2013;167:731-8.

8 Barrett-Connor E, Siris ES, Wehren LE, Miller PD, Abbott TA, Berger ML, et al. Osteoporosis and fracture risk in women of different ethnic groups. J Bone Miner Res 2005;20:185-94.

9 Seeley DG, Kelsey I, Jergas M, Nevitt MC. Predictors of ankle and foot fractures in older women. The Study of Osteoporotic Fractures Research Group. J Bone Miner Res 1996;11:1347-55.

10 Langer RD, White E, Lewis CE, Kotchen JM, Hendrix SL, Trevisan M. The Women's Health Initiative Observational Study: baseline characteristics of participants and reliability of baseline measures. Ann Epidemiol 2003;13(9 suppl):S107-21.

11 Cauley JA, Wampler NS, Barnhart IM, Wu L, Allison M. Chen Z, et al. Incidence of fractures compared to cardiovascular disease and breast cancer: the Women's Health Initiative Observational Study. Osteoporos Int 2008;19:1717-23.

12 Design of the Women's Health Initiative clinical trial and observational study. The Women's Health Initiative Study Group. Control Clin Trials 1998;19:61-109.

13 De Groot V Beckerman H, Lankhorst GI. Bouter LM. How to measure comorbidity. a critical review of available methods. J Clin Epidemiol 2003;56:221-9

14 Patterson RE, Kristal AR, Tinker LF Carter RA, Bolton MP, Agurs-Collins T. Measurement characteristics of the Women's Health Initiative food frequency questionnaire. Ann Epidemiol 1999;9:178-87.

15 Rosner B. Fundamentals of biostatistics. 6th ed. Thomson-Brooks/ Cole, 2006.

16 Stevens J, Couper D, Pankow J, Folsom AR, Duncan BB, Nieto FJ, et al. Sensitivity and specificity of anthropometrics for the prediction of diabetes in a biracial cohort. Obesity Res 2001;9:696-705.

17 Omsland TK, Schei B, Gronskag AB, Langhammer A, Forsen L, Gjesdal $\mathrm{CG}$, et al. Weight loss and distal forearm fractures in postmenopausal women: the Nord-Trondelag health study, Norway. Osteoporos Int 2009:20:2009-16.

18 Wilsgaard T, Jacobsen BK, Ahmed LA, Joakimsen RM, Stormer J, Jorgensen L. BMI change is associated with fracture incidence, but only in non-smokers. The Tromso Study. Osteoporos Int 2011;22:1237-45.

19 BeckTJ, Petit MA, Wu G, LeBoff MS, Cauley JA, Chen Z. Does obesity really make the femur stronger? BMD, geometry, and fracture incidence in the women's health initiative-observational study. J Bone Miner Res 2009;24:1369-79.

20 Sogaard Al, Meyer HE, Ahmed LA, Jorgensen L, Bjornerem A, Joakimsen RM, et al. Does recalled dieting increase the risk of non-vertebral osteoporotic fractures? The Tromso Study. Osteoporos Int 2012;23:2835-45

21 Chen Z, Kooperberg C, Pettinger MB, Bassford T, Cauley JA, LaCroix AZ, et al. Validity of self-report for fractures among a multiethnic cohort of postmenopausal women: results from the Women's Health Initiative observational study and clinical trials. Menopause 2004:11:264-74.

(C) BMJ Publishing Group Ltd 2015 